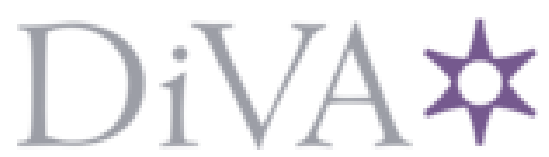

http://www.diva-portal.org

This is the published version of a chapter published in Teaching and Researching English Accents in Native and Non-native Speakers.

Citation for the original published chapter:

Cunningham, U. (2013)

Teachability and Learnability of English Pronunciation Features for Vietnamese-Speaking Learners.

In: E. Waniek-Klimczak \& L. R. Shockey (ed.), Teaching and Researching English Accents in Native and Non-native Speakers (pp. 3-14). Springer Berlin/Heidelberg

Second Language Learning and Teaching

http://dx.doi.org/10.1007/978-3-642-24019-5_1

N.B. When citing this work, cite the original published chapter.

Permanent link to this version:

http://urn.kb.se/resolve?urn=urn:nbn:se:su:diva-84254 


\title{
Teachability and Learnability of English Pronunciation Features for Vietnamese- Speaking Learners
}

\author{
Una Cunningham
}

\begin{abstract}
Anyone who has tried to learn a language with a very different sound system will understand the challenges faced by speakers of a language as different as Vietnamese who are attempting to learn to speak English in a way that is intelligible to non-speakers of Vietnamese. Many learners have very limited opportunity to hear model pronunciations other than their teacher's, and no opportunity at all to speak in English outside the classroom. Vietnamese-accented English is characterised by a number of features which ride roughshod over English morphosyntax, resulting in speech that is extremely difficult to reconstruct for the non-Vietnamese-speaking listener. Some of these features appear to be more difficult to learn to avoid than others. Phonotactic constraints in L1 appear to be persistent even in L2, and L1 phonological rules will, apparently, often apply in L2 unless they are blocked in some way. Perception of salient (to native listeners) target pronunciations is often lacking, and learners may not be aware that their pronunciation is not intelligible. Despite years of language study, many learners are unable to produce some native speaker targets. Vietnamese learners typically exhibit a set of characteristic pronunciation features in English, and the aim of this study is to see which of these are susceptible to remediation through explicit teaching. This explicit teaching is compared with a less direct, less interactive kind of teaching, involving drawing native and native-like pronunciation of problematic features of English pronunciation to the learners' attention. The results of this study can then be interpreted in terms of teachability and learnability, which do not always go hand in hand. If we understand what kinds of phonetic features are teachable and how learnability varies for different features, we can target those features where there is a good return for effort spent, resulting in efficient teaching.
\end{abstract}

\footnotetext{
U. Cunningham ( $\bowtie)$

University of Stockholm, Stockholm, Sweden

e-mail: una.cunningham@isd.su.se
} 


\section{Introduction}

One of the most mind-expanding experiences I have had in recent years has been attempting to learn Vietnamese at an age well past any critical period. I found that I was able to observe my pronunciation learning attempts - strategies I used to try to remember the exact quality of the high and mid-high back unrounded vowels and diphthong, and particularly how I tried to come to terms with the six tones used in Hanoi. The first challenge, as a first-time learner of a tone language is to notice the tones. Then comes a period of trying to distinguish them reliably from each other. The final challenge is to be able to produce tone in a way that is interpretable to listeners, first in isolated words, then in running speech.

The typological distance from English to Vietnamese is approximately equal to that between Vietnamese and English, and it is reasonable to assume that the kinds of difficulties I experienced in my attempts to pronounce Vietnamese are matched by different but comparable difficulties which face Vietnamese-speaking learners of English. Students have been heard to complain that it is difficult to remember how to pronounce words without tones, and the English vowel system offers a real challenge. English phonotactics is daunting and the semantic weight attached to the tongue-twisting clusters that burden every other English syllable sets the odds against success.

Vietnamese learners of English typically have a much tougher time with pronunciation than with syntactic or lexical acquisition. Vietnamese-accented speech is often difficult for non-speakers of Vietnamese to understand, even if the speaker can communicate well in written English. There are a number of reasons why this is so, and these have been the topic of previous work (Cunningham 2009b, c). The interesting observation that a non-native accent is generally more easily understood by other speakers of the same accent has been documented, e.g. by Jenkins (2002).

The fact that English pronunciation is not tested in the important national university entrance exams in Vietnam has, of course, a knock-on effect such that little effort is put into pronunciation in Vietnamese schools. On the other hand, the difficulty of English pronunciation for Vietnamese learners is legendary, and there is a feeling that the rewards of effort spent in the pursuit of better pronunciation are miserly. These conditions raise the twin questions of just how teachable and just how learnable English pronunciation is for these learners.

\section{Teachability of Pronunciation}

The concept of teachability of language was developed by Pienemann who wrote about it in connection with his Teachability hypothesis, suggesting that specific syntactical constructions could only be learned after mastery of parts of language that come earlier in second language development (Pienemann 1989). He also 
found that instruction has an accelerating effect on acquisition for learners who are ready for it (Pienemann 1984). This is not to be confused with the kind of teachability referred to by Tubbs who saw it as a property of the student rather than of the material to be learned (Tubbs 2003).

If, as has been suggested e.g. by Taylor (1993) and Jenkins (2000), Pienemann's model can be applied to pronunciation, it would suggest that while some undesirable features of L1 accents can be remedied informally, others are not affected by explicit teaching

Further, this approach implies that there is an order of acquisition of pronunciation features for second language learners, just as has been found for child language acquisition (Jakobson's 1942 order of acquisition steps). Examples of this are Demuth and McCullough (2009) and Kirk and Demuth (2005) working on the acquisition of clusters in French and English speaking children and Shillcock and Westermann (1997) on phonotactics, though Menn and Stoel-Gammon (1995) found inconsistencies in the order of acquisition of phonemes and allophones, and Dutch children have been found to vary in whether they acquire word-initial or word-final clusters first.

Factors other than the order of acquisition of pronunciation features may also affect the teachability of a particular pronunciation feature. The availability of pronunciation models is one such factor (Cunningham 2009a). Even with widespread access to the Internet, many Vietnamese learners do not regularly listen to English spoken by others than their teacher and classmates. Teachability can only be considered within a given educational context. The topic of this paper is the teachability of particular features of English pronunciation (as specified in targets relative to a particular pronunciation model) in a given educational setting with a given configuration of teachers and learners. It might be possible to alter the outcome of teaching by changing one or more of these parameters, such as the model, or the students' access to the model. The way the teaching is carried out may also be relevant.

After a recent conference in Ottowa, Derwing and Munro note that little work has, until recently, been oriented towards an examination of the efficacy of pronunciation teaching (Derwing Tracey and Munro Murray 2010). Traditionally research on L2 phonological acquisition has been concerned with learners errors, but Derwing and Munro point to more recent work which has been looking at the relationship between accent and intelligibility, cognitive processes underlying phonological learning, the evaluation of L2 speech, prosodic influences on the perception of accented speech, and the role of ethnic affiliation and identity in L2 speakers' oral production.

Celce-Murcia et al. (2010) list a number of ways pronunciation has been taught, with an emphasis on word-level accuracy. Pronunciation teaching can potentially involve many kinds of activities, such as:

- lectures and exercises on the phonetics of the model variety,

- extensive listening activities (listening for content),

- extensive speaking activities in a communicative learning context, 
- real communication outside the classroom (with or without feedback),

- intensive listening activities (listening for form) and noticing activities,

- listen and repeat activities with different kind of feedback:

- student listening in real time or to recording of own attempt,

- comment from peer or teacher, correction from peer of teacher,

- remodelling from teacher or recorded material,

- visual feedback (CALL),

- speech recognition feedback (peer, teacher or CALL).

It is extremely difficult to compare and evaluate the efficacy of these kinds of teaching. Typically learners will be exposed to several of these at a time, as well as other kinds of language work that are not specifically aimed at improving pronunciation, but which may well have an effect. The importance of interaction and feedback in the learning of pronunciation is often assumed, but there is little evidence to support this, and it is very difficult to measure the effect of this kind of input. Literature in this area is skimpy, and in an attempt to explore this further I have initiated a series of interviews with L2 speakers of English who have either worked with their accents or who have achieved near-nativeness in some respect. Results will be reported in future publications.

Might the persistence of some of the non-English-like features of the English produced by Vietnamese learners who are competent users of written English suggest that these pronunciation features are being taught in the wrong order? Or might the fact that even very advanced users of English fail to master some features of English pronunciation actually point to them not being learnable for these learners? Of course there are Vietnamese learners of English who do learn to pronounce English without the characteristic features associated with Vietnamese accents, but they may be applying other kinds of learning strategies than the usual ones.

\section{Learnability of Pronunciation}

There is no doubt that there are individuals who are more successful than others at achieving their targets for the learning of pronunciation. Some individuals acquire native-like pronunciation despite a late start and limited opportunities for interaction with native speakers of the target language. In at least some such cases the result is less due to unusual talent or aptitude than to hard work. Motivation and identity are also important factors in the equation. Some individuals feel that attempting to acquire a native-like accent is a rejection of their own culture which endangers their personal identity.

Some learners, perhaps particularly where there is a local variety of the target language, such as is the case for speakers of English in Nigeria or Pakistan, feel strongly that the local variety is the only legitimate target for their pronunciation, regardless of any problems this might cause when using English with speakers 
from outside this community. Others, with less personal identification or simply with less phonetic sensitivity, feel that a native-like accent is the obvious target for an ambitious language learner.

Jenkins, in her Lingua Franca core (Jenkins 2002), identified some features of English pronunciation as being more worthy than others of attention, at least if the target is to be intelligible to as wide a variety of native and non-native speakers of English as possible. For example, one of the features she mentioned as not being important for intelligibility and yet very difficult to acquire is the English interdental fricatives. Others have since then looked at various ways of ranking pronunciation targets. Scales et al., for example looked at learners' preferences, and found that learners preferred more intelligible accents (Scales et al. 2006). Others (unsurprisingly) have also found that listeners prefer speech that is intelligible to them (Burda and Hageman 2005; Kennedy and Trofimovich 2008; Munro and Derwing 1995; Volberg et al. 2006). Cunningham-Andersson and Engstrand isolated and elicited reaction to various features of Finnish-accented Swedish (Cunningham-Andersson and Engstrand 1989) and could rank individual features and combinations of features for the disturbance associated with them. But these rankings do not concern themselves with how possible it is for a learner to achieve the target.

It is generally held that repeated exposure is a significant factor in language learning (Cervantes and Gainer 1992; Flege et al. 1997). Learners need to meet new forms, be they grammatical structures, items of vocabulary or new sounds, in a number of contexts (Saragi et al. 1978) before they can be said to have learned them. The approach used in this study is an attempt to optimise the exposure of students to a limited set of pronunciation challenges faced specifically by Vietnamese learners of English. However important acquisition of a feature might be, some features seem to be particularly difficult for speakers of a given language to acquire.

\section{Vietnamese-Accented English}

Recent work by Cunningham outlines some of the more problematic issues for intelligibility Cunningham (2009a, b, c) in the speech of Vietnamese students of English. There are many segmental and suprasemental differences between the two languages, with English suprasegmentals being especially challenging for Vietnamese-speaking learners.

\subsection{Method}

This study is set in Hanoi College of Business and Tourism, a vocational further education college which has some 400 students per year. Their days are filled with timetabled teaching from morning to late afternoon, and they have very little time 
for unscheduled activities, even their own reading and listening work. The college language laboratory is not in use due to lack of funds for maintenance. Otherwise the classrooms in the college are not well suited to listening work. The sound environment in classrooms is quite poor as the doors and windows are generally open, to provide better airflow. There are fans rotating and the noise of the Hanoi traffic pervades everything. The classrooms have hard surfaces which reflect sound, and there are around 60 students in a class. Teachers generally use microphones to make themselves heard, and there is competition from the students' own conversation and mobile phone activity.

Though throughout Vietnam little emphasis is put on oral skills, at this particular Further education college, teaching staff and the college leadership are well aware of the importance of oral proficiency, perhaps particularly in the fields of business and tourism.

The author was invited to develop and deliver a short course in English pronunciation for 110 students of tourism in four classes at a College of Business and Tourism in Hanoi. Two courses were developed: first, a short course in pronunciation by listening, packaged as nine audio files was developed for three small classes (49 students in all). Secondly, an eight-lesson classroom course in pronunciation was delivered to 61 students in a single class. Specific pronunciation features are in focus in each session, dealing with specific needs of Vietnamese learners as established in earlier work (Cunningham 2009a, b). The focus of both the classroom and the audio file teaching is intelligibility. Students in Vietnam are not generally served by an aspiration to approach native-like pronunciation. The set of prioritised pronunciation targets for English as an International language proposed by Jenkins $(2002,2005)$ are broadly compatible with the features selected for the courses in this study.

The taught course was organised in eight sessions (two or three a week for three weeks). Each session concentrated on a particular aspect of the pronunciation of English, such as vowel quality, vowel duration, consonant articulation, final consonants, final clusters and initial clusters. A typical session began with general chitchat about the weather or the traffic or what had been going on since the last class, to allow the students to hear and get used to the speech of the teacher and for the braver students to interact with the teacher. Then the topic for the day's class was introduced and modelled for the students to hear. Contrasts between sounds were demonstrated in isolation and in running speech, and the students were asked to try to discriminate between contrasting sounds and words (e.g. nine, line, Nile), firstly in the teacher's speech, and then in their partner's speech. Students worked in pairs, attempting to produce the target sounds initially in a way such that their partner could reliably know which of two or three contrasting sentences they were reading. Finally, groups of students were each asked to nominate a speaker to produce the contrasting sentences for the teacher to distinguish.

The remaining students were each given an mp3-player with nine short lessons recorded on it. The lessons covered the same points as the taught sessions. Each lesson had a text for the students to listen to, comments from the teacher, and then 
excerpts from the text illustrating the use of the target sounds which were the topic for that session.

Before and after the intervention, each student in both groups was recorded by an assistant reading a text, sentences and words designed to elicit the features which are focussed on in the classroom and podcasted courses, such as vowel quality and duration, initial and final consonants. The sentences were:

1. Please sit on this little white seat. These wide black seats are still wet.

2. Can you ask his sister not to hiss and scream if she scolds him when he's late?

3. Bring me five sheep skins and four goat skins after lunch.

4. She can see him with sixteen sheep not six tin ships.

In addition, the groups were given an opportunity to give written feedback about the courses, and this was complemented by interviews with teachers on their view of the course and the material. The ten phonetic features in focus for the teaching material were selected on the basis of previous work on the intelligibility of the English spoken by Vietnamese speakers (Cunningham 2009c). They include some of the most problematic characteristic features of the English spoken by Vietnamese-speaking learners:

1. distinction between the vowels of ship and sheep,

2. the pronunciation of dental fricatives,

3. final clusters (regardless of morpheme boundaries, e.g. seats, ask, six),

4. initial glides (wet, wide, one),

5. distinction between/n/and/l/(lunch, school),

6. temporal, glottal or fortis/lenis distinction to mark postvocalic consonant voicing (his-hiss, white-wide),

7. initial clusters (scream, scold),

8. elision of the coda (wet, late),

9. distinction between the first sounds in see and she,

10. distinction between/f/and/p/(e.g. in if and after).

For each speaker, a point was given for each of the features pronounced in a target-like way, so that a speaker could score a maximum of ten points for each recording. The results for the group before and after the intervention were tested using two-tailed $t$ tests.

\subsection{Results}

In the taught course the mean score for the 10 pronunciation features for the students before the teaching began was $4.24(\mathrm{n}=50)$ which means that they on average successfully pronounced 4.24 of the 10 target pronunciations. In the $\mathrm{mp3}$-group the average score before the students received the mp3-players was marginally higher $4.77(\mathrm{n}=43)$. A two-tailed student's $t$ test shows that this 


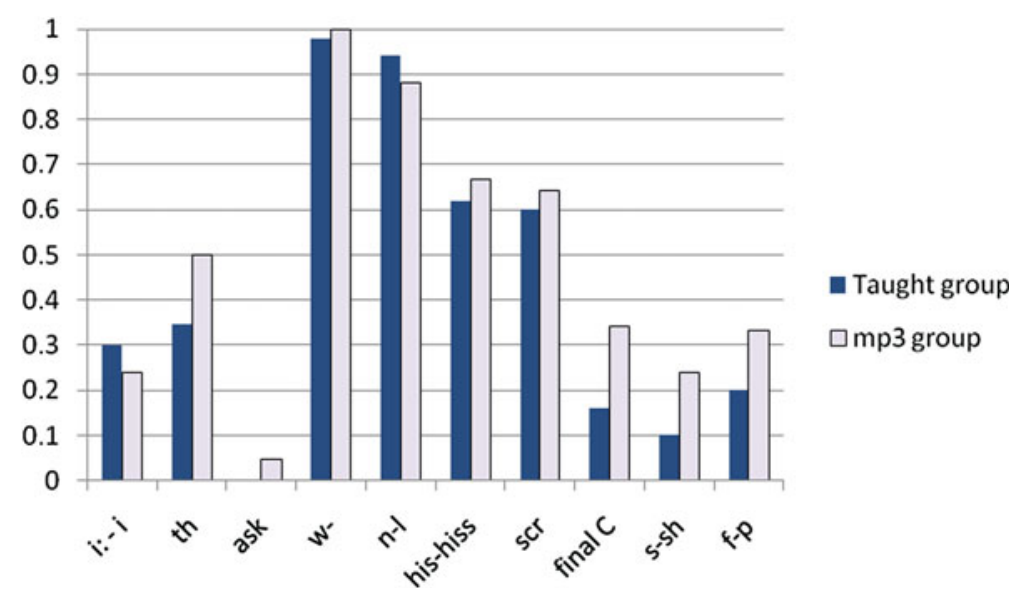

Fig. 1 Comparison between the groups at the beginning of the study broken down by the ten phonetic features which were observed in the students' pronunciation and focused on in the teaching sessions and podcasts

difference between the classes before the teaching began was weakly significant $(\mathrm{p}(\mathrm{t})=0.047)$.

The taught class includes 61 students. Fifty of these students chose to participate in the study after full information was given to them, and 51 took part in the final recording. In the mp3-group, 42 took part in the initial recording and only 32 of these took part in the final recording. Figure 1 shows the breakdown for the comparison between the two groups before the start of the intervention by pronunciation feature.

Notice that there is not much difference between the groups. The only feature difference that is significant (at the $5 \%$ level) is feature 8 , the pronunciation of the final stop in words like wet, where the mp3 group had, on average, a more targetlike pronunciation, with a clear stop being made more often.

Figure 2 shows a breakdown of the results before and after the eight teaching sessions. Notice the large improvement in the ability of students in six of the ten observed points (features marked * show improvements significant at the $5 \%$ level and those marked ** are significant at the $1 \%$ level): to distinguish between the vowels in seat, sheep and sit, ship (feature $1^{* *}$ ), to pronounce interdental fricatives (feature $2^{*}$ ), to make postvocalic voicing distinctions (feature $6^{*}$ ), to pronounce a clear/t/at the end of words like wet and seat (feature $8^{*}$ ), to distinguish between the initial sounds in see and she (feature $9^{* *}$ ) and to pronounce final/f/as [f] rather than [p] (feature 10**). Of the other four features studied, the students had not much difficulty with features 4 and 5 already at the start of the study, while they still could not master final clusters (feature 3 ) at all by the end of the study, and there was no improvement in their ability to pronounce initial clusters at the end of the study. 


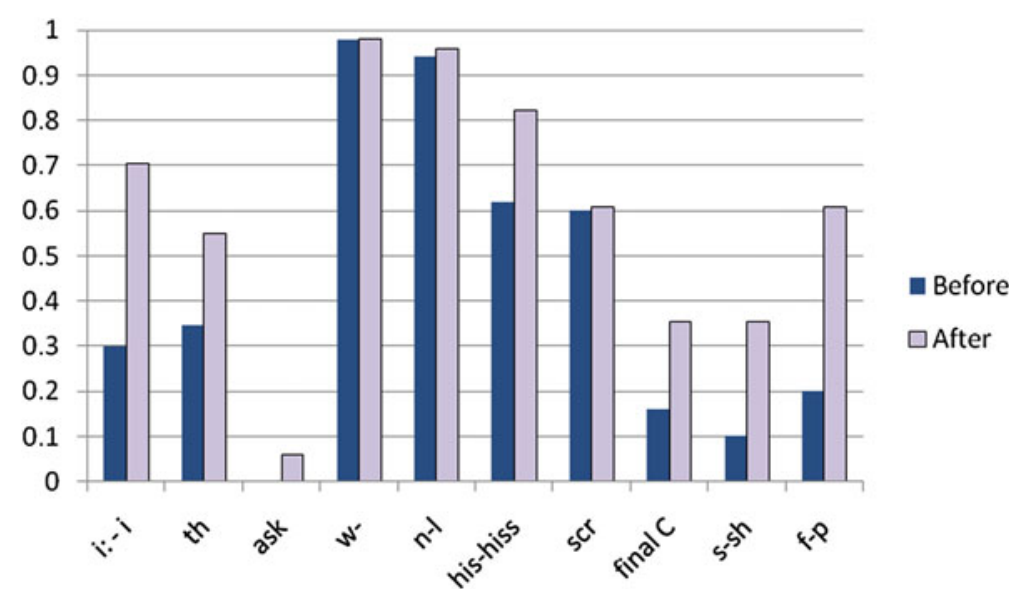

Fig. 2 Comparison for the taught group before and after the study, broken down by the ten phonetic features which were observed in the students' pronunciation and focused on in the teaching sessions

In no case is there a significant difference for the group which was given the mp3 players with the prerecorded audio lessons. It has to be concluded that the mp3 group made no progress whatsoever as measured by this study.

\section{Discussion}

These students have had very little opportunity to speak English with non-Vietnamese speakers and for most of them this was their first close encounter with a "westerner". Thus the teaching sessions meant a huge increase to their exposure to a native speaker of English with all that entails in terms of quantity of speech material they hear and are required to engage with, and the rigorous requirements placed on their speech when they were required to speak in class in such a way that a native-speaking interlocutor could understand their speech. This required many repetitions and in many cases the students had to resort to writing down what they wanted to say. This was, of course, a disappointment to them and their teacher. However, the taught group appears to have benefitted significantly from the eight teaching sessions they received.

In terms of the teachability and learnability of individual pronunciation features, it seems that consonant clusters, both initial and final, are particularly resistant to learning. Vietnamese phonotactic constraints mean that there are no clusters in Vietnamese words or loan words, and there are severe limitations on what is admissible in the coda of syllables. The initial cluster production was about $60 \%$ accurate, and there was no change in this during the period of the study. There were very few instances of target-like production of final clusters in either 
group of these students either before or after the intervention period. So in Peinemann's terms (op cit), perhaps the students are not ready to learn the production of final clusters at this stage, and thus cannot be helped by teaching. Jenkins $(2000,119)$ claims that "where the difficulty with an L2 English pronunciation feature is universal", which is perhaps true of the fiendishly complex final clusters offered by languages like English, "we are looking at an item that may well be unteachable". Initial clusters seem to be easier for these learners to acquire than final clusters.

It is interesting to set this finding alongside studies of children's L1 acquisition of clusters. Studies of the L1 acquisition of English, where there is a morphological advantage for early acquisition of final clusters show that final clusters are acquired before initial clusters (Kirk and Demuth 2005). Initial clusters were, however, observed to be acquired before final clusters by French-speaking infants by Demuth and McCullough (Demuth and McCullough 2009). They attribute the fact that complexity appears at the beginning of words before at the ends of words to French not having heavy word-final morphophonology, unlike English. They also point to possible alternative syllable analyses that may leave final consonants in French final clusters in another syllable than a preceding consonant. They further suggest that final clusters are typologically more marked than initial clusters and thus potentially likely to be acquired later.

The features that were most susceptible to change due to the intervention, the difference between sheep and ship, the difference between /p/ and /f/ and between $/ \int /$ and $/ \mathrm{s} /$ are perhaps easily demonstrated by a teacher, with appropriate exaggeration of the differences to help students to become aware that there is a difference. The three features where there was a less but still significant difference due to the intervention, interdental fricatives, release of final $/ t /$ and the use of vowel lengthening to signal post vocalic voicing were also fairly easy to demonstrate, and to work with. The remaining two features, the difference between /1/ and $/ \mathrm{n} /$ and initial $/ \mathrm{w} /$ were not very problematic for most students in this group even before the intervention.

Unfortunately, the $\mathrm{mp} 3$ group in this study made no progress. This could have a number of explanations. Firstly, it may be the case that the basic premise of this study is flawed. Practice listening to English (extensive listening) and having features of English pronunciation in use be brought to one's attention (intensive listening) may not actually be helpful to students. Secondly, it may be that the students did not actually listen to the material in the way intended. Thirdly, it may be that the students listened once through the material and then did not listen again, thus not gaining enough exposure to the material to make a difference. This could be because they found the material too difficult or simply uninteresting, or because they were not motivated to spend time on this work. This means that although the study did show a gratifying improvement in the specific pronunciation features studied for the taught group, this study cannot show an effect of listening on pronunciation. Obviously further studies are required here, perhaps with a student group that can be more closely followed and supported for a longer period. 


\section{References}

Burda, Angela Noel, and Hageman, Carlin F. (2005). Perception of accented speech by residents in assisted-living facilities. Journal of Medical Speech-Language Pathology, 13(1), 7-14.

Celce-Murcia, Marianne, Brinton, Donna and Goodwin, Janet M. (2010). Teaching Pronunciation : A Course Book and Reference Guide (2 ed.). Cambridge: Cambridge University Press.

Cervantes, Raoul, \& Gainer, Glenn. (1992). The effects of syntactic simplification and repetition on listening comprehension. TESOL Quarterly, 26(4), 767-770.

Cunningham, Una. (2009a). Models and targets for English pronunciation in Vietnam and Sweden. Research in Language 7, 113-128.

Cunningham, Una. (2009b). Phonetic correlates of unintelligibility in Vietnamese-accented English. Paper presented at the FONETIK 2009 The XXIIth Swedish Phonetics Conference. Available at http://www2.ling.su.se/fon/fonetik_2009/108\%20cunningham_fonetik2009.pdf.

Cunningham, Una. (2009c). Quality, quantity and intelligibility of vowels in Vietnameseaccented English. In Ewa Waniek-Klimczak (Ed.), Issues in Accents of English II: Variability and Norm. Newcastle: Cambridge Scholars Publishing Ltd.

Cunningham-Andersson, Una \& Engstrand, Olle. (1989). Perceived strength and identity of foreign accent in Swedish. Phonetica, 46(4), 138-154.

Demuth, Katherine \& McCullough, Elizabeth. (2009). The longitudinal development of clusters in French. Journal of Child Language, 36(2), 425-448.

Derwing, Tracey. M., \& Munro, Murray. J. (2010). Symposium - Accenting the positive: Directions in pronunciation research. Language Teaching, 43(3), 366-368.

Flege, James Emil, Bohn, Ocke-Schwen, \& Jang, Sunyoung. (1997). Effects of experience on non-native speakers' production and perception of English vowels. Journal of Phonetics, 25(4), 437-470.

Jakobson, Roman. (1942). Kindersprache, Aphasie und allgemeine Lautgesetze. Uppsala: Uppsala Universitets årsskrift 9.

Jenkins, Jennifer. (2000). The Phonology of English as an International Language. Oxford: Oxford University Press.

Jenkins, Jennifer. (2002). A sociolinguistically based, empirically researched pronunciation syllabus for English as an international language. Applied Linguistics, 23(1), 83-103.

Jenkins, Jennifer. (2005). Implementing an international approach to English pronunciation: The role of teacher attitudes and identity. TESOL Quarterly, 39(3), 535-543.

Kennedy, Sara \& Trofimovich, Pavel. (2008). Intelligibility, comprehensibility, and accentedness of L2 speech: The role of listener experience and semantic context. Canadian Modern Language Review-Revue Canadienne Des Langues Vivantes, 64(3), 459-489.

Kirk, Cecilia, \& Demuth, Katherine. (2005). Asymmetries in the acquisition of word-initial and word-final consonant clusters. Journal of Child Language, 32(4), 709-734.

Menn, Lise, \& Stoel-Gammon, Carol. (1995). Phonological development. In Paul Fletcher \& Brian MacWhinney (Eds.), The Handbook of Child Language. Oxford: Blackwell.

Munro, Murray. J., \& Derwing, Tracey. M. (1995). Foreign accent, comprehensibility, and intelligibility in the speech of 2nd-language learners. Language Learning, 45(1), 73-97.

Pienemann, Manfred. (1984). Psychological constraints on the teachability of languages. Studies in Second Language Acquisition, 6(2), 186-214.

Pienemann, Manfred. (1989). Is language teachable? Psycholinguistic experiments and hypotheses. Applied Linguistics 10(1), 52-79.

Saragi, Thomas, Nation, Ian Stephen Paul, \& Meister, Gerold Fritz. (1978). Vocabulary learning and reading. System, 6(2), 72-78.

Scales, Julie, Wennerstrom, Ann., Richard, Dara, \& Wu, Su Hui. (2006). Language learners' perceptions of accent. TESOL Quarterly, 40(4), 715-738.

Shillcock, Richard, and Westermann, Gert. (1997) The role of phonotactic range in the order of acquisition of English consonants. In Wolfram Ziegler \& Karin Deger (Eds.) Clinical Linguistics and Phonetics. London: Whurr. 
Taylor, David S. (1993). Intonation and accent in English: What teachers need to know. International Review of Applied Linguistics in Language Teaching, 31(1), 425-435.

Tubbs, Nigel (2003). The concept of "teachability". Educational Theory, 53(1), 75-91.

Volberg, Leonie, Kulka, Marko, Sust, Charlotte. A., \& Lazarus, Hans. (2006). Speech intelligibility and the subjective assessment of speech quality in near real communication conditions. Acta Acustica United with Acustica, 92(3), 406-416. 